\title{
Adolescent perceptions of resilience-promoting resources: the South African Pathways to Resilience Study
}

\author{
Angelique C van Rensburg (Optentia), \\ Linda C Theron (University of Pretoria \& Optentia) \\ Sebastiaan Rothmann (Optentia)
}

\begin{abstract}
Resilience, or being well-adjusted despite facing adversity that predicts negative life outcomes, is a process that is scaffolded by resilience-enabling supports. How well resilience-enabling resources support positive adjustment depends, in part, on adolescents' perceptions of the availability and usefulness of such resources. Currently, there is limited quantitative, generalisable evidence of the aforementioned. Accordingly, the purpose of this study was to document how two groups of Sesotho-speaking adolescents perceived available social-ecological resources and how significantly varied perceptions related to these adolescents' use of formal supports. The advisory panel to the Pathways to Resilience Study clustered participating adolescents into a resilient group $(n=221)$ and vulnerable, or service-using, group $(n=186)$. In comparison with the service-using adolescents, resilient adolescents reported significantly higher perceptions of physical and psychological caregiving. Analyses of variance revealed that higher perceptions of caregiving were associated with higher voluntary and lower mandatory service usage. We concluded that relationship-building was a crucial resilience mechanism and would, therefore, encourage psychologists to both prioritise and facilitate caregiving.
\end{abstract}

\section{Keywords}

Adolescent perceptions, caregiving, measurement invariance, Pathways to Resilience Youth Measure, resilience, South Africa

Resilience, or doing better than expected despite hardship, is a process of complex and dynamic interactions that facilitate positive outcomes (Cicchetti, 2013; Masten, 2014; Rutter, 2012). From a social-ecological perspective, this process requires adolescents and their social ecologies (i.e., the relational and organisational systems in which the adolescent is nested) to co-contribute to resilience-enabling interactions (Ungar, 2015). Social-ecological stakeholders (such as parents,

Optentia Research Focus Area, North-West University, South Africa; Department of Educational Psychology, Faculty of Education, University of Pretoria, South Africa

Corresponding author:

Angelique C van Rensburg, Optentia Research Focus Area, North-West University, Vaal Triangle Campus, PO Box I I74, Vanderbijlpark, 1900, South Africa.

Email: angelique@angeliquevanrensburg.com 
service providers, or policy makers) support the process of resilience by making relevant resilience-enabling resources (e.g., good schools, mentorship opportunities) available and accessible. Adolescents contribute to the resilience process when they utilise the aforementioned resources and/or when they petition adults to provide resources that are unavailable at that point in time and that are likely to support positive developmental outcomes (Ungar, 2011, 2012).

The above definition implies that resource provision is insufficient to support resilience (Hopkins, Zubrick, \& Taylor, 2014; Ungar, 2013). Adolescent uptake of provided resources is important to resilient outcomes and depends, in part, on how accessible and meaningful resources are to adolescents (Panter-Brick, 2015). Additionally, some resources have greater or lesser protective value, depending on the stressor being encountered, the level of risk experienced, and other socio-demographic factors (e.g., developmental stage or gender; Hopkins et al., 2014; Ungar et al., 2015; Wright, Masten, \& Narayan, 2013). Because attention to how resource use shapes the achievement of positive outcomes is limited (Ungar, 2013), this article reports a crosssectional study that investigated 407 Sesotho-speaking adolescents' perceptions of socialecological supports and how these perceptions related to their use of social-ecological services.

\section{A social-ecological approach to resilience}

Adjusting well to adverse life circumstances has more to do with how social ecologies support atrisk adolescents and less with the strengths and resources of adolescents themselves (Ungar et al., 2015). One way in which social ecologies provide meaningful support is via formal resources, such as schools or social and mental health supports (Baum et al., 2013; Mota \& Matos, 2015). For example, 'growth-fostering relationships' with community professionals (e.g., a nurse and psychologist) have been associated with the resilience of HIV/AIDS-infected and/or -affected adolescents in residential care in South Africa (SA; Pienaar, Swanepoel, van Rensburg, \& Heunis, 2011, p. 133).

Formal social-ecological supports can be subcategorised into mandatory and voluntary resources. Mandatory resources are formal services (e.g., foster homes, substance-abuse programmes) that adolescents are legally required to use. Such requirements usually relate to adverse life circumstances/events (e.g., dysfunctional family contexts or neglect/abuse) or risktaking behaviours (e.g., criminal acts or substance abuse). In contrast, voluntary resources (e.g., support educators, a helpline, or community recreation programmes) are those that adolescents choose to use to cope well with adverse life circumstances/events (Ungar, Liebenberg, Dudding, Armstrong, \& van de Vijver, 2013). Use of voluntary and/or mandatory resources is associated with adolescent resilience (Ungar, 2012). For example, a New Zealand study demonstrated that vulnerable adolescents benefitted from engagement with school counsellors whom they had been mandated to see as well as from more informal connections to caring teachers (Sanders, Munford, Thimasarn-Anwar, Liebenberg, \& Ungar, 2015).

Social-ecological support can also be informal. Generally, informal supports are embedded within naturally occurring relationships - adolescents' relationship with their community, peers, family members, and culture (Sanders et al., 2015; Zautra, 2014). For instance, Theron, Theron, and Malindi (2013) reported that love and care from family members (particularly grandmothers), positive peer support, community promotion of constructive values, and spirituality supported Basotho adolescents to accommodate the challenges of structural disadvantage. 


\section{Use of social-ecological resources is varied}

Even though social ecologies offer supports (i.e., informal and/or formal resources), use of these resources is typically diverse. This variation relates, in part, to the perceived availability of relational and contextual resources (Ungar, 2012). For example, Theron and Theron (2014) reported that a resilient student elicited support from a teacher because she perceived this teacher as being available and accessible. None of the youth in this study reported psychologists as being instrumental to their resilience; the structural disadvantage that challenged these adolescents precluded reliable access to mental health services.

Varied resource use also relates to the meaning adolescents attach to resources. When adolescents experience resources as being relevant to, and/or respectful of, their cultural and contextual positioning, they are more likely to value and use them (Panter-Brick, 2015). For example, Ungar et al. (2013) found that Canadian adolescents were more likely to value formal services if staff offering the service respected adolescents' cultural backgrounds, personal values, and religious beliefs. Similarly, van Rensburg, Theron, Rothmann, and Kitching (2013) reported limited significant (albeit small) relationships between service use and resilience; when adolescent satisfaction with the services was accounted for, larger significant associations were present.

The meaningfulness of resources also relates to risk. Some resources are more or less meaningful, depending on the type of risk, the level of risk experienced, and other sociodemographic factors (e.g., developmental stage or gender; Hopkins et al., 2014; Ungar, 2015; Wright et al., 2013). For example, Kliewer et al. (2006) reported that family cohesion was less likely to curb the risk of drug abuse among adolescents living in Panama and Costa Rica when exposure to community violence was high. This related, in part, to adolescents at high risk of exposure being less inclined to use family resources. At lower levels of risk, family cohesion was predictably protective.

\section{This study}

Internationally, the variability of adolescents' informal/formal resource use is fairly well documented in qualitative research, but there is little generalisable evidence of adolescents' differential perceptions of resilience-promoting resources (Ungar, 2013). The same is true locally: two systematic reviews of youth resilience studies indicated an absence of quantitative accounts of diverse resource usage and how adolescents' varied perceptions of resources related to formal resource use (Theron \& Theron, 2010; van Rensburg, Theron, \& Rothmann, 2015). Thus, first, this article aims to investigate adolescents' self-reported perceptions of socialecological resources and how these perceptions might/might not differ across two distinct groups, from the same social ecology, representing higher and lower risk exposure levels (see section 'Method'). The authors considered this comparison worthwhile, given the recent call in resilience literature to better understand whether resource use was uniform for adolescents who shared a geographical context, but who were differently risk exposed (Hopkins et al., 2014; Ungar, 2015; Wright et al., 2013). Second, this article investigates how significantly varied perceptions of resilience-promoting resources relate to adolescents' reported use of formal supports.

\section{Method}

The Pathways to Resilience Study investigated adolescent resilience in Canada, China, Colombia, New Zealand, and SA (see www.resilienceproject.org). The SA investigation took place in the Thabo Mofutsanyane District, Free State province. It included 1137 adolescents (Theron et al., 2013). Adolescents living in this district experience multiple daily risks related to 
high unemployment, violent crime, poor infrastructure, poverty, poor service delivery, and HIV/AIDS (Berry, Biersteker, Dawes, Lake, \& Smith, 2013). An SA advisory panel (AP), comprising 11 local adults who provided daily services to adolescents (see Theron et al., 2013), ensured that data collection (including the wording and contents of the survey) and ethical procedures were contextually relevant and culturally congruent (Theron, 2013).

\section{Participants}

For the purpose of this article, a subset of the SA Pathways data was purposefully chosen. It comprised survey data generated by 407 participants (211 girls, 195 boys, one undisclosed). Participants were $13-19$ years old $(M=15.62$ years, standard deviation $[S D]=1.74$ years $)$, with Grades 3-12 completed $(M=7.60, S D=1.73)$. The majority $(97.05 \%)$ self-identified as Black. This purposeful sample consisted of two groups: one that the AP identified as resilient $(n=221)$ and one as less resilient (i.e., service-using (SU) sample; $n=186$ ). As detailed in Theron et al. (2013), using a grounded theory approach, the AP and the Pathways team interacted to determine a local understanding of the key indicators of resilience. The outcome was that the AP associated resilience with youth capacity to be future-oriented, value-driven, invested in education, and stoical, and with youth access to an active support network. These criteria have been previously reported in the international resilience literature (Werner, 2013) and the South African resilience literature (Theron \& Theron, 2010), albeit using different terms (e.g., optimism or goaldirectedness for future-oriented). The AP then invited teachers and service providers to nominate children who fitted the above criteria (who were willing to participate) to the project. We acknowledge that it is possible that children who were differently resilient from the criteria identified by the AP would have been excluded from the 'resilient' sample.

Additionally, the Department of Social Development (DSD) had not required participants in this group to make use of social or mental health services in the 6 months preceding the study. In contrast, at the time of the study, participants in the second group (SU) had been required by the DSD to make use of social services, including institutional care and substance-use programmes. The AP associated such obligatory service use with vulnerability and high risk for negative developmental outcomes. The participants in the second group were nominated to the project by service providers with whom the AP had contact and voluntarily agreed to participate.

Independent $t$-tests indicated that no statistically significant differences were present between the SU and resilient samples on age, $t(404)=-.74, p=.46$; grade passed, $t(401)=-.93, p=.35$; school attendance, $t(404)=-.65, p=.52$; and perceptions of their community as violent, $t(398)=-.10, p=.92$.

\section{Instruments}

The Pathways to Resilience Youth Measure (PRYM; Resilience Research Centre, 2010) is a composite self-report survey that measures resilience-promoting resources, mental health outcomes, risks, and service usage (see http://goo.gl/HRx7oA). For this article, the following PRYM scales/subscales (all Likert-type scales) were used to measure the constructs integral to the aim of this article (i.e., adolescents' perceptions of social-ecological risk and resources, and their personal mental health). Table 1 indicates the reliability of the scales in this study.

Perceptions of resilience-promoting resources. Three subscales (i.e., personal [11 items; $\alpha=.80$ ], physical and psychological caregiving [7 items; $\alpha=.83$ ], and contextual resources [10 items; 
$\alpha=.79]$ ) of the Child Youth Resilience Measure (Liebenberg, Ungar, \& van de Vijver, 2013) were employed, using a 5-point scale ranging from Not at all to A lot.

Table I. Correlation matrix and reliability of constructs.

\begin{tabular}{|c|c|c|c|c|c|c|c|c|c|c|c|}
\hline \multicolumn{2}{|c|}{ Variable } & $\rho$ & I & 2 & 3 & 4 & 5 & 6 & 7 & 8 & 9 \\
\hline \multicolumn{12}{|c|}{$\overline{S U}$} \\
\hline I. & $\begin{array}{l}\text { Personal } \\
\text { resources }\end{array}$ & .87 & & & & & & & & & \\
\hline 2. & $\begin{array}{l}\text { Physical and } \\
\text { psychological } \\
\text { caregiving }\end{array}$ & .88 & $.70 * *$ & & & & & & & & \\
\hline 3. & $\begin{array}{l}\text { Contextual } \\
\text { resources }\end{array}$ & .89 & $.95^{* *}$ & $.72 * *$ & & & & & & & \\
\hline 4. & $\begin{array}{l}\text { Antisocial } \\
\text { behaviour }\end{array}$ & .91 & $-.32^{* *}$ & $-.25 * *$ & $-.35 * *$ & & & & & & \\
\hline 5. & $\begin{array}{l}\text { Health risk } \\
\text { behaviour }\end{array}$ & .96 & $-\left..4\right|^{* *}$ & $-.42 * *$ & $-.48 * *$ & $.68^{* *}$ & & & & & \\
\hline 6. & $\begin{array}{l}\text { Disruptive } \\
\text { behaviour }\end{array}$ & .58 & $-.43 * *$ & $-.35 * *$ & $-.47^{* *}$ & $.70 * *$ & $.73^{* *}$ & & & & \\
\hline 7. & $\begin{array}{l}\text { Negative peer } \\
\text { support }\end{array}$ & .92 & $-.22 *$ & $-.30 * *$ & $-.21 *$ & $.50 * *$ & $.66^{* *}$ & $.47^{* *}$ & & & \\
\hline 8. & $\begin{array}{l}\text { Poor caregiver } \\
\text { presence }(R)\end{array}$ & .90 & $-.34 * *$ & $-.36 * *$ & $-.37 * *$ & .01 & $.20^{*}$ & .17 & .03 & & \\
\hline 9. & $\begin{array}{l}\text { Lack of community } \\
\text { safety }(R)\end{array}$ & y.35 & $-.40 * *$ & $-.48 * *$ & $-.47^{* *}$ & .08 & $.43^{* *}$ & .05 & $.51 * *$ & .22 & \\
\hline & $\begin{array}{l}\text { Barriers to } \\
\text { community/school } \\
\text { participation }\end{array}$ & .81 & .06 & -.09 & .04 & $.53^{* *}$ & $.32^{* *}$ & $.47^{* *}$ & .10 & .00 & .31 \\
\hline \multicolumn{12}{|c|}{ Resilient } \\
\hline & $\begin{array}{l}\text { Personal } \\
\text { resources }\end{array}$ & .86 & & & & & & & & & \\
\hline 2. & $\begin{array}{l}\text { Physical and } \\
\text { psychological } \\
\text { caregiving }\end{array}$ & .92 & $.85^{* *}$ & & & & & & & & \\
\hline 3. & $\begin{array}{l}\text { Contextual } \\
\text { resources }\end{array}$ & .87 & $.96 * *$ & $.7 \mid * *$ & & & & & & & \\
\hline 4. & $\begin{array}{l}\text { Antisocial } \\
\text { behaviour }\end{array}$ & .89 & $-.32 * *$ & $-.35 * *$ & $-.37 * *$ & & & & & & \\
\hline 5. & $\begin{array}{l}\text { Health risk } \\
\text { behaviour }\end{array}$ & .95 & $-.42^{* *}$ & $-.48 * *$ & $-.44 * *$ & $.84 * *$ & & & & & \\
\hline 6. & $\begin{array}{l}\text { Disruptive } \\
\text { behaviour }\end{array}$ & .68 & $-.54 * *$ & $-.52 * *$ & $-.56 * *$ & $.69 * *$ & $.64^{* *}$ & & & & \\
\hline 7. & $\begin{array}{l}\text { Negative peer } \\
\text { support }\end{array}$ & .93 & $-.49 * *$ & $-.4 I^{* *}$ & $-.49 * *$ & $.40^{* *}$ & $.65^{* *}$ & $.50 * *$ & & & \\
\hline 8. & $\begin{array}{l}\text { Poor caregiver } \\
\text { presence }(R)\end{array}$ & .95 & $-.22^{* *}$ & $-.20 *$ & $-.27^{* *}$ & .10 & .17 & .09 & .09 & & \\
\hline 9. & $\begin{array}{l}\text { Lack of community } \\
\text { safety }(R)\end{array}$ & $y .53$ & $-.42^{* *}$ & $-.4 I^{* *}$ & $-.36 * *$ & .17 & $.27^{* *}$ & $.20 *$ & $.33 * *$ & .04 & \\
\hline & $\begin{array}{l}\text { Barriers to } \\
\text { community/school } \\
\text { participation }\end{array}$ & .84 & $-.35^{* *}$ & $-.35^{* *}$ & $-.32 * *$ & $.63^{* *}$ & $.50 * *$ & .66 ** & $.22 *$ & .04 & $.20 *$ \\
\hline
\end{tabular}


$\rho:$ reliability; SU: service-using sample; R: reversed.

$* p<.05 ; * * p<.01$.

Perceptions of mental health outcomes. Two subscales of the 4-H Study of Positive Youth Development (Phelps et al., 2007) were used. The delinquency subscale (five items; $\alpha=.73$ ) measured antisocial behaviour on a 5-point scale ranging from Never to Five or more times. The risk subscale (nine items; $\alpha=.86$ ) measured health risk behaviour on a 4-point scale ranging from Never to Regularly. The conduct problems subscale (five items; $\alpha=.80$ ) of the Strengths and Difficulties Questionnaire (Goodman, 2001) measured disruptive behaviour. Using a 3-point scale, response options included False, Sometimes, and True.

Perceptions of risks. From the 4-H Study of Positive Youth Development (Lerner et al., 2005; Phelps et al., 2007), the community/school participation subscale (five items; $\alpha=.76$ ) measured barriers to community/school participation on a 3-point scale ranging from Not at all to A lot. The National Longitudinal Study of Children and Youth Brief Questionnaire (NLSCY; four items; $\alpha=.72$ ) measured negative peer support (van Rensburg, 2014). Response options ranged from None to All on a 4-point scale. The Ontario Student Drug Use and Health Survey (OSDUHS; three items; $\alpha=.81$ ) measured poor caregiver presence (Liebenberg et al., 2016). Response options ranged from No days to Five days or more on a 6-point scale. The Boston Neighbourhood Survey (BNS; six items; $\alpha=.54$ ) measured lack of community safety (van Rensburg, 2014). Response options ranged from Not at all to A lot on a 3-point scale.

Service usage. The 39 items of the Youth Services Survey (YSS; Resilience Research Centre, 2010) measured formal supports used in the last 6 months, including mandatory (i.e., foster placements, substance abuse or addiction services) and voluntary (i.e., counsellors, educators, traditional healers) services. Response options included Never, Once, Couple of times, Three times or more, and Could not get service.

\section{Procedure}

Under the guidance of researchers and in groups (30-45), adolescents self-completed the PRYM after school hours. Three Sesotho-speaking fieldworkers assisted in the administration of the PRYM. Following AP advice, the PRYM was not translated. The AP was confident that the youths' English-medium education would scaffold understanding of most survey items. With the exception of 22 words (most of which related to concepts that were less familiar [occupational therapy; psychiatry] or American terms [bunk, affection]), their assumption was verified during the piloting of the PRYM. Thus, fieldworkers read the PRYM aloud and used predetermined code switches (i.e., synonyms in Sesotho that were agreed to by the AP) when adolescents were uncertain of the aforementioned 22 terms.

\section{Ethical considerations}

The North-West University and the Department of Basic Education, Free State province, SA, provided ethical clearance for the research. Participation was voluntary and anonymous. Participants had the right to withdraw at any time. Written participant and caregiver assent/consent preceded study participation. 


\section{Data analysis}

Confirmatory factor analysis (CFA) was performed in Mplus 7.2 (Muthén \& Muthén, 19982016) to test the validity of factor structures of measures to test measurement invariance between the SU and resilient samples. It is good practice to test the validity of factor structures beforehand to ensure that measures (which might have been developed elsewhere in the world) are valid for the context in which they are used. Furthermore, it is necessary to test measurement invariance prior to testing for potential group differences (Wang \& Wang, 2012). A categorical estimator was employed, specifically a weighted least square estimator (WLSMV), which made use of modified $\chi^{2}$ statistics to better deal with 3- to 6-point Likert scales utilised in the PRYM (Resilience Research Centre, 2010). Statistics used to test model fit were chi-square $\left(\chi^{2}\right)$, degrees of freedom $(d f)$, Tucker-Lewis Index (TLI), comparative fit index (CFI), root mean square error of approximation (RMSEA), and RMSEA 90\% confidence intervals (CIs) and their significance $(p)$. Scores higher than .90 for TLI/CFI and RMSEA estimates and CIs smaller than $.08(p>.05)$ indicated close fit of the model (Byrne, 2012). Cronbach's alphas should not be used to calculate reliability when latent variables are used, since the assumption that every item contributes equally to a latent variable (i.e., tau-equivalence) is violated; therefore, point-estimate reliabilities ( $\rho)$ were calculated (Raykov, 2012).

Some adolescent resilience studies (Goel, Amatya, Jones, \& Ollendick, 2014; Jung et al., 2012; Stokar, Baum, Plischke, \& Ziv, 2014) compare means of constructs/items by assuming that factor loadings and thresholds/intercepts are invariant between groups. This approach potentiates item and construct bias. To avoid the aforementioned, measurement invariance was employed in Mplus 7.2 before comparing the resilient and SU samples (He \& van de Vijver, 2015; Muthén \& Muthén, 1998-2016). A baseline model (measurement model) was tested for acceptable fit in both samples independently (resilient and SU samples). Once acceptable fit had been established, the authors tested for measurement invariance.

Finally, latent variable factor scores were imported into SPSS 22.0 (IBM Corp., 2015). An analysis of variance (ANOVA) was employed to analyse the data generated by adolescents' completion of the YSS to understand whether adolescents' varied perceptions (if any) of resilience-promoting resources were associated with their reported use of formal supports.

\section{Results}

\section{Measurement model}

A measurement model was developed within the SU sample to simulate resilience-promoting resources, risks, and mental health outcomes adolescents perceived within their social ecology. The model consisted of 10 first-order latent variables: personal resources, physical and psychological caregiving, contextual resources, antisocial behaviour, health risk behaviour, disruptive behaviour, negative peer support, poor caregiver presence, lack of community safety, and barriers to community/school participation.

The developed model (SU sample; CFI $=.94$, TLI $=.94, \mathrm{RMSEA}=.03,90 \%$ CI [.02, .03], $p>.05)$ was verified in the resilient sample $(\mathrm{CFI}=.96$, TLI $=.96, \mathrm{RMSEA}=.02,90 \% \mathrm{CI}[.02$, $.03], p>.05)$. The levels of significance of CIs in both samples were greater than .05 , indicating that the model had close fit. Also, fit indices revealed that the 10-factor measurement/baseline model could be employed as a configural model during invariance testing. All but three (SU sample: RISK3: $\rho=.58$ and RISK6: $\rho=.35$; resilient sample: RISK6: $\rho=.53$ ) latent variables showed acceptable point-estimate reliability (Table 1 ). 


\section{Measurement invariance}

Three hierarchical steps were followed to examine measurement invariance: configural, metric/weak, and scalar/strong invariance.

Table 2. Measurement invariance.

\begin{tabular}{lllllllllll}
\hline & MI & $\chi^{2}$ & $d f$ & $\Delta \chi^{2}$ & $\Delta d f$ & $p$ & CFI & TLI & RMSEA & $90 \% \mathrm{Cl}$ \\
\hline I. & Configural model & 4904.74 & 4301 & & & & .95 & .95 & .03 & {$[.02, .03]^{*}$} \\
2. Full weak/metric & & $4998.5 \mathrm{I}$ & 4357 & 128.21 & 56 & .00 & .94 & .94 & .03 & {$[.02, .03]^{*}$} \\
$\begin{array}{l}\text { invariance } \\
\text { 3. Revised weak/ } \\
\text { metric invariance }\end{array}$ & 57.28 & 4945.12 & 4356 & 67.00 & 55 & .13 & .95 & .95 & .03 & {$[.02, .03]^{*}$} \\
4. $\begin{array}{l}\text { Full strong (scalar) } \\
\text { invariance }\end{array}$ & 5032.39 & 4421 & 129.78 & 65 & .00 & .95 & .95 & .03 & {$[.02, .03]^{*}$} \\
5. Revised strong/ & 21.50 & 5010.73 & 4420 & 90.17 & 64 & .02 & .95 & .95 & .03 & {$[.02, .03]^{*}$} \\
$\begin{array}{l}\text { scalar invariance } \\
\text { Revised strong/ } \\
\text { scalar invariance }\end{array}$ & 8.88 & 5003.57 & 4419 & 76.66 & 63 & .12 & .95 & .95 & .03 & {$[.02, .03]^{*}$} \\
\hline
\end{tabular}

Ml: modification index; $d f$ : degrees of freedom; $\Delta \chi^{2}$ : change in chi-square; $\Delta d f$ : change in degrees of freedom; $p$ : obtained significance; CFI: comparative fit index; TLI: Tucker-Lewis Index; RMSEA: root mean square error of approximation; Cl: confidence interval.

$* p<.05$.

Configural invariance. The configural model, a model where all parameters were constrained (i.e., factor loadings and intercepts were not assumed to be equal between groups), was specified, and acceptable fit was established (see Table 2). A $p$-value $>.05$ with regard to the RMSEA CIs indicated close fit $(\mathrm{CFI}=.95, \mathrm{TLI}=.95, \mathrm{RMSEA}=.03,90 \%$ CI $[.02, .03], p>.05)$. Findings showed configural invariance across the SU and resilient samples. The authors proceeded to more restrictive multi-group analyses.

Metric/weak invariance. The configural model was compared to a metric model that allowed factor loadings between the SU and resilient samples to be invariant. A significant $\Delta \chi^{2}$ indicated that the SU and resilient samples were significantly different $\left(\Delta \chi^{2}=128.21, \Delta d f=56, p=.00\right)$. A modification index (MI) of 57.28 indicated that the factor loading on health risk behaviour ('How many times in the past year have you done the following things: used dagga?') was variant. The parameter was, subsequently, freed in both samples. Partial metric invariance was then achieved $\left(\Delta \chi^{2}=67.00, \Delta d f=55, p=.13\right)$, indicating that if the one item identified above was removed, the factor loadings between the SU and resilient samples were invariant.

Scalar/strong invariance. The metric model was compared to a scalar model that also constrained thresholds; a significant $\Delta \chi^{2}$ indicated that the SU and resilient samples were significantly different $\left(\Delta \chi^{2}=129.78, \Delta d f=65, p=.00\right)$. An MI of 21.50 indicated that an item on health risk behaviour ('How many times in the past year have you done the following things: used dagga/cannabis?') was variant; the constraint on the item was freed in both samples and still a significant $\Delta \chi^{2}$ was observed $\left(\Delta \chi^{2}=90.17, \Delta d f=64, p=.02\right)$. The MIs (8.88) indicated that a disruptive behaviour item ('To what extent do the sentences describe you: I do as I am told?') was variant. The constraint on the item was freed in both samples. Partial scalar invariance was attained $\left(\Delta \chi^{2}=76.66, \Delta d f=63, p=.12\right.$; see Table 2$)$. 


\section{Latent variable mean differences}

Two biased items, discussed above, were removed to ensure at least strong/scalar invariance (van de Schoot, Lugtig, \& Hox, 2012). Acceptable fit was achieved for the revised multi-group model $(\mathrm{CFI}=.95, \mathrm{TLI}=.95, \quad \mathrm{RMSEA}=.03,90 \% \mathrm{CI}[.02, .03], p>.05)$. The results indicated significantly higher latent variable mean scores regarding physical and psychological caregiving $(\Delta M=.34, p=.01)$ in the resilient sample. The mean scores of antisocial behaviour $(\Delta M=.47$; $p=.00)$ and disruptive behaviour $(\Delta M=.18 ; p=.01)$ were significantly higher in the SU sample. Other scores were invariant.

\section{ANOVA}

Since latent variable difference analyses indicated that only physical and psychological caregiving varied significantly, their association with formal support usage was calculated. Factor scores were exported from Mplus 7.2, and ANOVAs were performed. Among the resilient sample, higher perceptions of physical and psychological caregiving were associated with more frequent usage of voluntary resources such as doctors $(F=3.25, d f=4, p=.01)$, support groups (e.g., Soul Buddyz; $F=3.43, d f=4, p=.01)$, support educators $(F=4.59, d f=4, p=.00)$, traditional healers $(F=4.99, d f=4, p=.00)$, and helplines $(F=3.91, d f=4, p=.00)$. In the resilient sample, significantly higher perceptions of caregiving were associated with less frequent historic usage of mandatory services such as social work services $(F=4.30, d f=4, p=.00)$, foster homes $(F=4.71, d f=4, p=.00)$, substance-abuse programmes $(F=9.62, d f=4, p=.00)$, and hospital treatment for mental health issues $(F=3.90, d f=4, p=.01)$. Higher perceptions of physical and psychological caregiving in the SU sample were only associated with decreased use of substance-abuse programmes $(F=4.74, d f=4, p=.00)$.

\section{Discussion}

First, the results of this study confirmed that adolescents at higher and lower levels of risk (i.e., as identified by the AP) had similar, but also significantly varied, perceptions of resiliencepromoting resources. This variation fits in with more recent arguments that resource use is not uniform across risk levels (Cicchetti, 2013; Masten, 2014; Rutter, 2012). In particular, adolescents' perceptions differed significantly with regard to physical and psychological caregiving resources. This was despite adolescents from both groups reporting similar perceptions of caregiver presence. Regardless of similar caregiver presence, the SU sample perceived depressed physical and psychological caregiving (e.g., emotional support, food, shelter). Apparently, the mere presence of caregivers does not guarantee experiences of caregiving.

The SU sample's significantly lower perception of caregiving might reflect their mandated living arrangements (e.g., residence in children's homes). Such residence is associated with decreased physical and psychological caregiving, mostly due to poor bonding between adolescents and substitute caregivers (e.g., housemothers; Altena, Beijersbergen, \& Wolf, 2014; Groark, McCall, McCarthy, Eichner, \& Gee, 2013). Another possible reason for decreased perceptions of care among SU participants relates to their self-reported elevated risk for antisocial and disruptive behaviours. Hofelich and Preston (2014) reported that service providers and other adults were less likely to care for individuals who were challenging to interact with. It is plausible that the disruptive behaviour of the SU adolescents shaped caregivers' actions and attitudes and perhaps strained their inclination to care. 
Significantly lower perceptions of caregiving possibly also relate to the SU samples being members of a structurally disadvantaged community. There is some evidence that adolescents from disadvantaged contexts experience less caregiving, even though caregivers are physically present (Brown, Ackerman, \& Moore, 2013; Jeon, Buettner, \& Hur, 2014). This relates to working-class caregivers being too tired/careworn to provide physical and/or psychological care (Mogotiane, Chauke, van Rensburg, Human, \& Kganakga, 2010; Nduna \& Jewkes, 2012). However, such circumstantial hypotheses do not explain the resilient sample's significantly elevated perceptions of caregiving. They, too, came from families that were challenged by poverty where, arguably, caregivers were tired/careworn as well. This raises questions about what influences adolescents' perceptions of caregiving sources and urges qualitative follow-up. Simultaneously, these young people's experience prompts an investigation into what enables some caregivers to apparently engage with their children, regardless of how structural obstacles challenge relationship-building. The resulting insights could be used to inform relationshipbuilding interventions.

Second, the results offered proof that significantly higher perceptions of physical and psychological caregiving were associated with increased use of formal voluntary supports and decreased use of mandatory formal supports. Apparently, perceptions of care go together with help-seeking behaviours. Given the emphases of earlier and current resilience studies on the importance of relational capital to resilience (see, for example, Luthar, 2006), this finding is not surprising. Again, however, it prompts follow-up studies because it is unclear whether perceptions of caregiving pre-empted health-seeking behaviours, or vice versa.

Increased perceptions of physical and psychological caregiving were also associated with the resilient sample's decreased historic use of mandatory supports and the SU sample's lower historic and current use of substance-abuse programmes - also a mandatory support. This fits in with the systematic review by Ryan, Jorm, and Lubman (2010), which associated caregiving (in particular, monitoring, support, and adolescent-caregiver connections) with decreased adolescent alcohol use. Possibly, higher perceptions of caregiving decrease self-harming behaviours (such as substance abuse), thereby decreasing the need for/use of mandatory supports such as substanceabuse programmes.

The above must be understood against four limitations. First, given the cross-sectional nature of the collected data, this study provides a time-limited understanding of adolescents' varied perceptions of resilience-promoting resources and how these relate to formal support usage. Second, the authors did not investigate the invariance of means of sex and age groups because the sample sizes were too small to assess measurement invariance (Byrne, 2012). Third, without qualitative data/causal designs, what informed adolescents' varied perceptions of caregiving resources cannot be explained. Consequently, follow-up phenomenological and/or quasiexperimental studies are necessary (Monette, Sullivan, \& DeJong, 2011). Finally, the PRYM is a self-report measure. Self-report instruments are mostly associated with the likelihood of item and construct biases, even though some literature argues against this (Haeffel \& Howard, 2010). Also, the authors acknowledge that the use of some subscales of the PRYM may have been problematic since it was not developed within the South African context. This limitation is more pronounced for the Disruptive Behaviour and Lack of Community Safety subscales which demonstrated low reliability scores. However, the AP-guided adaptation of the PRYM (i.e., rewording American-like and/or culturally insensitive phrasing) did provide some support for face and content validity. In addition, acceptable fit statistics in both independent samples support the validity of the subscales in this sample of young people. 


\section{Conclusion}

Using the current findings, psychologists are advised to promote relational resources (i.e., psychological and physical caregiving) when working with SU adolescents. This implies supporting them to behave in ways that will elicit constructive caregiving responses as well as teaching caregivers to prioritise relationship-building and to understand that caregiving involves more than caregiver presence. Furthermore, psychologists themselves should facilitate caregiving experiences in their interaction with adolescent clients.

It is no coincidence that poor attachment and weak relational bonding are associated with residence in structurally disadvantaged communities (Nduna \& Jewkes, 2012). Knowing that risk and resilience are largely socially determined (Parchment, Small, Osuji, McKay, \& Bhana, 2016), it is not enough to teach caregivers to prioritise relationships that provide physical and psychological care. Social ecologies must be adapted in ways that will address/alleviate structural and socio-political barriers to caregiving. To this end, psychologists and others should lobby for law and policy change that will support equitable social ecologies.

\section{Funding}

The author(s) received financial support from the IDRC, Canada for the research, authorship, and/or publication of this article.

\section{References}

Altena, A. M., Beijersbergen, M. D., \& Wolf, J. R. L. M. (2014). Homeless youth's experiences with shelter and community care services: Differences between service types and the relationship to overall service quality. Children and Youth Services Review, 46, 195-202. doi:10.1016/j.childyouth.2014.08.019

Baum, N., Cardozo, B., Pat-Horenczyk, R., Ziv, Y., Blanton, C., Reza, A., . . Brom, D. (2013). Training teachers to build resilience in children in the aftermath of war: A cluster randomized trial. Child \& Youth Care Forum, 42, 339-350. doi:10.1007/s10566-013-9202-5

Berry, L., Biersteker, L., Dawes, H., Lake, L., \& Smith, C. (2013). South African child gauge 2013. Cape Town, South Africa: University of Cape Town.

Brown, E. D., Ackerman, B. P., \& Moore, C. A. (2013). Family adversity and inhibitory control for economically disadvantaged children: Preschool relations and associations with school readiness. Journal of Family Psychology, 27, 443-452. doi:10.1037/a0032886

Byrne, B. M. (2012). Structural equation modeling with Mplus: Basic concepts, applications, and programming. New York, NY: Taylor \& Francis.

Cicchetti, D. (2013). Annual research review: Resilient functioning in maltreated children - Past, present, and future perspectives. Journal of Child Psychology and Psychiatry, 54, 402-422. doi:10.1111/j.14697610.2012.02608.x

Goel, K., Amatya, K., Jones, R., \& Ollendick, T. (2014). Child and adolescent resiliency following a residential fire: The role of social support and ethnicity. Journal of Child \& Family Studies, 23, $537-$ 547. doi:10.1007/s10826-013-9715-4

Goodman, R. (2001). Psychometric properties of the strengths and difficulties questionnaire. Journal of the American Academy of Child and Adolescent Psychiatry, 40, 1337-1345. doi:10.1097/00004583200111000-00015

Groark, C. J., McCall, R. B., McCarthy, S. K., Eichner, J. C., \& Gee, A. D. (2013). Structure, caregiverchild interactions, and children's general physical and behavioral development in three Central American institutions. International Perspectives in Psychology: Research, Practice, Consultation, 2, 207-224. doi:10.1037/ipp0000007

Haeffel, G. J., \& Howard, G. S. (2010). Self-report: Psychology's four-letter word. American Journal of Psychology, 123, 181-188. doi:10.5406/amerjpsyc.123.2.0181

He, J., \& van de Vijver, F. J. R. (2015). The value of keeping an open eye for methodological issues in research on resilience and culture. In L. Theron, L. Liebenberg, \& M. Ungar (Eds.), Youth resilience and culture: Complexities and commonalities (pp. 189-201). Dordrecht, The Netherlands: Springer. 
Hofelich, A. J., \& Preston, S. D. (2014). Different strokes: Empathy, individual characteristics, and helping. In M. Kent, M. C. Davis, J. W. Reich, M. Kent, M. C. Davis, \& J. W. Reich (Eds.), The resilience handbook: Approaches to stress and trauma (pp. 247-255). New York, NY: Routledge/Taylor \& Francis.

Hopkins, K. D., Zubrick, S. R., \& Taylor, C. L. (2014). Resilience amongst Australian Aboriginal youth: An ecological analysis of factors associated with psychosocial functioning in high and low family risk contexts. PLoS ONE, 9(7), e102820. doi:10.1371/journal.pone.0102820

IBM Corp. (2015). IBM SPSS Statistics for Windows, Version 23.0 [Computer software]. Armonk, NY: Author.

Jeon, L., Buettner, C. K., \& Hur, E. (2014). Family and neighborhood disadvantage, home environment, and children's school readiness. Journal of Family Psychology, 28, 718-727. doi:10.1037/fam0000022

Jung, Y.-E., Min, J.-A., Shin, A. Y., Han, S. Y., Lee, K.-U., Kim, T.-S., . . Chae, J.-H. (2012). The Korean version of the Connor-Davidson Resilience Scale: An extended validation. Stress \& Health, 28, 319326. doi:10.1002/smi. 1436

Kliewer, W., Murrelle, L., Prom, E., Ramirez, M., Obando, P., Sandi, L., \& Del Carmen Karenkeris, M. (2006). Violence exposure and drug use in Central American youth: Family cohesion and parental monitoring as protective factors. Journal of Research on Adolescence, 16, 455-478. doi:10.1111/j.15327795.2006.00502.x

Lerner, R. M., Lerner, J. V., Alermigi, J., Theokas, C., Phelps, E., Gestsdottir, S., . . . Bobek, D. (2005). Positive youth development, participation in community youth development programs, and community contributions of fifth grade adolescents: Findings from the first wave of the 4-H study of positive youth development. Journal of Early Adolescence, 25, 17-71. doi:10.1177/0272431604272461

Liebenberg, L., Theron, L., Sanders, J., Munford, R., van Rensburg, A. C., Rothmann, S., \& Ungar, M. (2016). Bolstering resilience through teacher-student interaction: Lessons for school psychologists. School Psychology International, 37, 140-154. doi:10.1177/0143034315614689

Liebenberg, L., Ungar, M., \& van de Vijver, F. (2013). Validation of the Child and Youth Resilience Measure-28 (CYRM-28) among Canadian youth. Research on Social Work Practice, 22, $219-226$. doi:10.1177/1049731511428619

Luthar, S. S. (2006). Resilience in development: A synthesis of research across five decades. In D. Cicchetti \& D. J. Cohen (Eds.), Developmental psychopathology: Risk, disorder, and adaptation (pp. 739-759). Hoboken, NY: Wiley.

Masten, A. S. (2014). Global perspectives on resilience in children and youth. Child Development, 85, 6-20. doi:10.1111/cdev.12205

Mogotiane, S. M., Chauke, M. E., van Rensburg, G. H., Human, S. P., \& Kganakga, C. M. (2010). A situational analysis of child-headed households in South Africa. Curationis, 33(3), 24-32. Retrieved from http://www.curationis.org.za/index.php/curationis/article/view/4

Monette, D. R., Sullivan, T. J., \& DeJong, C. R. (2011). Applied social research (8th ed.). Belmont, MA: Brooks/Cole.

Mota, C. P., \& Matos, P. M. (2015). Adolescents in institutional care: Significant adults, resilience and wellbeing. Child \& Youth Care Forum, 44, 209-224. doi:10.1007/s10566-014-9278-6

Muthén, L. K., \& Muthén, B. O. (1998-2016). Mplus user's guide (7th ed.). Los Angeles, CA: Author.

Nduna, M., \& Jewkes, R. (2012). Disempowerment and psychological distress in the lives of young people in Eastern Cape, South Africa. Journal of Child \& Family Studies, 21, 1018-1027. doi:10.1007/s10826011-9564-y

Panter-Brick, C. (2015). Culture and resilience: Next steps for theory and practice. In L. Theron, L. Liebenberg, \& M. Ungar (Eds.), Youth resilience and culture: Complexities and commonalities (pp. 223-244). Dordrecht, The Netherlands: Springer.

Parchment, T. M., Small, L., Osuji, H., McKay, M., \& Bhana, A. (2016). Familial and contextual influences on children's prosocial behavior: South African caregivers as adult protective shields in enhancing child mental health. Global Social Welfare, 3, 1-10.

Phelps, E., Balsano, A. B., Fay, K., Peltz, J. S., Zimmerman, S. M., Lerner, R. M., \& Lerner, J. V. (2007). Nuances in early adolescent developmental trajectories of positive and problematic/risk behaviors: Findings from the 4-H Study of Positive Youth Development. Child and Adolescent Psychiatric Clinics of North America, 16, 473-496. doi:10.1016/j.chc.2006.11.006 
Pienaar, A., Swanepoel, Z., van Rensburg, H., \& Heunis, C. (2011). A qualitative exploration of resilience in pre-adolescent AIDS orphans living in a residential care facility. Journal of Social Aspects of HIV/AIDS, 8, 128-137. doi:10.1080/17290376.2011.972499

Raykov, T. (2012). Scale construction and development using structural equation modeling. In R. H. Hoyle (Ed.), Handbook of structural equation modeling (pp. 472-492). New York, NY: Guilford Press.

Resilience Research Centre. (2010). The pathways to resilience research manual. Halifax, Nova Scotia, Canada: Author. Retrieved from http://resilienceresearch.org/

Rutter, M. (2012). Resilience: Causal pathways and social ecology. In M. Ungar (Ed.), The social ecology of resilience: A handbook of theory and practice (pp. 33-42). New York, NY: Springer.

Ryan, S. M., Jorm, A. F., \& Lubman, D. I. (2010). Parenting factors associated with reduced adolescent alcohol use: A systematic review of longitudinal studies. Australian and New Zealand Journal of Psychiatry, 44, 774-783. doi:10.1080/00048674.2010.501759

Sanders, J., Munford, R., Thimasarn-Anwar, T., Liebenberg, L., \& Ungar, M. (2015). Research article: The role of positive youth development practices in building resilience and enhancing wellbeing for at-risk youth. Child Abuse \& Neglect, 42, 40-53. doi:10.1016/j.chiabu.2015.02.006

Stokar, Y., Baum, N., Plischke, A., \& Ziv, Y. (2014). The key to resilience: A peer based youth leader training and support program. Journal of Child \& Adolescent Trauma, 7, 111-120. doi:10.1007/s40653014-0016-x

Theron, L. (2013). Community-researcher liaisons: The Pathways to Resilience Project advisory panel. South African Journal of Education, 33(4), 1-19.

Theron, L., \& Theron, A. M. C. (2010). A critical review of studies of South African youth resilience, 1990-2008. South African Journal of Science, 106(7-8), 1-8. doi:10.4102/sajs.v106i7/8.252

Theron, L., \& Theron, A. M. C. (2014). Education services and resilience processes: Resilient black South African students' experiences. Children and Youth Services Review, 47, 297-306. doi:10.1016/j.childyouth.2014.10.003

Theron, L., Theron, A. M. C., \& Malindi, M. J. (2013). Toward an African definition of resilience: A rural South African community's view of resilient Basotho youth. Journal of Black Psychology, 39, 63-87. doi: $10.1177 / 0095798412454675$

Ungar, M. (2011). The social ecology of resilience: Addressing contextual and cultural ambiguity of a nascent construct. American Journal of Orthopsychiatry, 81, 1-17. doi:10.1111/j.19390025.2010.01067.x

Ungar, M. (2012). Social ecologies and their contribution to resilience. In M. Ungar (Ed.), The social ecology of resilience: A handbook of theory and practice (pp. 13-31). New York, NY: Springer.

Ungar, M. (2013). Resilience, trauma, context, and culture. Trauma, Violence, \& Abuse, 14, 255-266. doi: $10.1177 / 1524838013487805$

Ungar, M. (2015). Resilience and culture: The diversity of protective processes and positive adaptation. In L. Theron, L. Liebenberg, \& M. Ungar (Eds.), Youth resilience and culture: Commonalities and complexities (pp. 37-48). Dordrecht, The Netherlands: Springer.

Ungar, M., Liebenberg, L., Dudding, P., Armstrong, M., \& van de Vijver, F. J. R. (2013). Patterns of service use, individual and contextual risk factors, and resilience among adolescents using multiple psychosocial services. Child Abuse \& Neglect, 37, 150-159. doi:10.1016/j.chiabu.2012.05.007

Ungar, M., Theron, L., Liebenberg, L., Tian, G.-X., Restrepo, A., Sanders, J., . . Russell, S. (2015). Patterns of individual coping, engagement with social supports and use of formal services among a fivecountry sample of resilient youth. Global Mental Health, 2, e21. doi:10.1017/gmh.2015.19

van de Schoot, R., Lugtig, P., \& Hox, J. (2012). A checklist for testing measurement invariance. European Journal of Developmental Psychology, 9, 486-492. doi:10.1080/17405629.2012.686740

van Rensburg, A. C. (2014). A social-ecological investigation of African youths' resilience processes (Unpublished doctoral dissertation). North-West University, Vanderbijlpark, South Africa.

van Rensburg, A. C., Theron, L., \& Rothmann, S. (2015). A review of quantitative studies of South African youth resilience: Some gaps. South African Journal of Science, 111(7-8), 1-9. doi:10.17159/sajs.2015/20140164

van Rensburg, A. C., Theron, L., Rothmann, S., \& Kitching, A. (2013). The relationship between services and resilience: A study of Sesotho-speaking youths. Social Work Practitioner-Researcher, 25, 286-308.

Wang, J., \& Wang, X. (2012). Structural equation modelling: Applications using Mplus. Hoboken, NJ: Wiley. 
Werner, E. E. (2013). What can we learn about resilience from large scale longitudinal studies? In S. Goldstein \& R. B. Brooks (Eds.), Handbook of resilience in children (pp. 87-102). New York, NY: Springer.

Wright, M. O., Masten, A. S., \& Narayan, A. J. (2013). Resilience processes in development: Four waves of research on positive adaptation in the context of adversity. In S. Goldstein \& R. B. Brooks (Eds.), Handbook of resilience in children (pp. 15-37). New York, NY: Springer.

Zautra, A. J. (2014). Resilience is social, after all. In M. Kent, M. C. Davis, \& J. W. Reich (Eds.), The resilience handbook: Approaches to stress and trauma (pp. 185-196). New York, NY: Routledge. 